members of the Genesee County Dental Society agree to take every opportunity to instruct those coming under our care concerning this problem, and especially parents with reference to the need of beginning the care of the teeth of their children at $2 \frac{1}{2}$ or 3 years of age, as soon as erupted, as the only means of preventing serious mouth infection.

That we agree to give all children coming under our care competent and conscientious attention, or if unable to give the time to do this, to refer these children to one whom we believe can.

That we further endorse the start made by the Dental Division of the Health Department of the City of Flint, in endeavoring to meet this situation by free dental clinics and recommend that our Common Council and School Board extend this work as rapidly as sound policy will permit in the direction of providing this department facilities for simple dental operations in each school building, where most of the work needed can be done with the greatest economy of the dentist's time and with the least interference with the school time of the child.

We further endorse, as the aim of this department, that it endeavor to have all infection removed and preventive polishing and filling performed for as many children as possible, making the greatest effort first in the lower grades and endeavoring eventually, as the department grows, to bring all our children to the end of their grammer grades without infection, dead or lost teeth.

We recommend that this department should urge, upon those who can afford it, the advantage of competent private care with its more frequent examinations and attention to matters of perfection which are not practical in the public dental clinic; but we believe that no child should be denied the invaluable service of the removal of infection and preventive filling, or polishing, because the parents cannot or will not provide for the same elsewhere. Surely every child is as much entitled to health as to education."

\title{
A METHOD FOR PREPARING BACTERIOLOGIC MEDIA CONTAINING ASCITES FLUID.
}

\author{
By LINWOOD G. GRACE, D. D. S., Cleveland, Ohio.
}

(From the Laboratories of the Research Institute of the National Dental Association, Cleveland, Ohio.)

$\mathrm{T}$ HE use of broth to which certain amounts of ascites fluid are added has been advocated for some time for cultivating streptococci and other organisms. The usual directions given for its preparation are that the sterile fluid be added to the broth ' which has been previously made and sterilized. The method requires most careful attention to details and offers numerous sources for contamination. If the fluid has not been collected aseptically, it can, of course, be sterilized by passing thru an unglazed porcelain filter. There still 
remains, however, the problem of getting it into tubes of broth in definite quantities without contamination. H. Bierry (Comptes Rendus des Seames de la Société de Biologie, 1916, No. 7, p. 270) called attention to the fact that ascites and other albuminous fluids may be autoclaved at $112^{\circ} \mathrm{C}$. without coagulating, if previously rendered alkaline. It may then be neutralized and reautoclaved and still remain clear. Or it may be added to broth or agar, the reaction of which is adjusted as required, and autoclaved without causing coagulation or precipitation in the media.

It is quite obvious that such a process infinitely simplifies the preparation of such a media. The ascites can be added to the broth or agar in definite amounts before it is tubed. This is far more accurate than adding it to the media after it has been tubed and also less laborious.

In order to determine the minimum amount of alkali necessary to add to ascites fluid to prevent coagulation when autoclaved, we carried out the following experiment:

The sample of ascites on hand was nearly neutral. Phenolphthalein was used as the indicator. Twenty test tubes were selected and into each test tube were placed 10 c.c. of ascites fluid. Definite amounts of alkali were added to each tube and all autoclaved at 15 pounds pressure, $118^{\circ}$ C., for 15 minutes. This is slightly higher than the temperature suggested by Bierry, but is the standard we have used for some time for autoclaving media. After autoclaving, all those which were still liquid were filtered. A separate tube in which no alkali was added was run as a control. As a final test a few drops of a normal acid solution were added to each tube. A flocculent precipitate was thrown down in each case upon the addition of the first drop of acid.

From the results of the experiment it would appear that six or seven drops of 40 per cent $\mathrm{NaOH}$ to each 10 c.c. of ascites, or about $2 \mathrm{I} / 2$ per cent alkali, gave the best results. However, before adding the alkali, the ascites should be titrated, as a more acid fluid would undoubtedly need a greater amount of alkali to produce the same results. It is better to add small quantities of a strong alkali than large quantities of a weak one on account of diluting the fluid.

When the ascites is received it is rendered alkaline by adding $2 \mathrm{~T} / 2$ per cent of 40 per cent $\mathrm{NaOH}$, autoclaved 15 pounds at $118^{\circ} \mathrm{C}$. for 15 minutes and stored in the ice box until ready for use. When the media is made up this ascites is added in the required amounts, usually 5 per cent, the reaction of the entire batch adjusted, filtered, tubed, and autoclaved 15 pounds at $118^{\circ} \mathrm{C}$. for 15 minutes. We have been using this method for over a year, and results have shown that all organisms tested grow equally as well as in media prepared by the old method.

Reprint from The Journal of Iaboratory and Clinical Medicine, St. Louis, Vol. V, No. 4, January, 1920. 